\title{
Environmental Flows from Alternate Land Uses in the Delta, Pacific, and the Southeastern States: 1947-2007
}

\author{
Charles B. Moss, Andrew Schmitz* \\ Food and Resource Economics Department, University of Florida, Gainesville, FL, USA \\ Email: ${ }^{*}$ aschmitz@ufl.edu
}

Received 8 September 2014; revised 2 October 2014; accepted 24 October 2014

Copyright (C) 2014 by authors and Scientific Research Publishing Inc.

This work is licensed under the Creative Commons Attribution International License (CC BY).

http://creativecommons.org/licenses/by/4.0/

(c) () Op Open Access

\begin{abstract}
Land use policy involves allocating land between production alternatives to meet society's wants and desires. Increase in the affluence in the United States has increased the demand for environmental flows that could be met from public ownership or as joint products of private ownerships. The empirical results of this study indicated that land use patterns remained relatively unchanged between 1947 and 2007. The lack of change suggests that a large part of the demand for environmental services is being as byproducts of other commercial decisions.
\end{abstract}

\section{Keywords}

Environmental Flows, Information Theory, Complementary Slackness

\section{Introduction}

This study examines the changes in land use between 1947 and 2007 focusing on the possibility that commercial uses generate significant environmental benefits. In the early twentieth century, land distributions under the Land Ordinance of 1790 as modified by the Homestead Act of 1862 came to a close. While vast tracts in the United States remained under the control of the federal and state governments, private land ownership was limited. Once the distributions from public land had been limited, land in private hands started to accrue rents (i.e., no additional land could be brought into production-increasing the rent accruing land previously in production under Ricardo's model). These increased rents from commercial uses of land increased the opportunity cost of less intensive uses of land. In addition, urban growth increased the demand for the conversion of farmland into residential and other urban uses. Taken together, higher rents from agricultural and the increased demand for

\footnotetext{
"Corresponding author.
}

How to cite this paper: Moss, C.B. and Schmitz, A. (2014) Environmental Flows from Alternate Land Uses in the Delta, Pacific, and the Southeastern States: 1947-2007. Journal of Environmental Protection, 5, 1531-1540. 
urban uses are typically hypothesized to reduce the amount of land generating environmental services.

The increasing affluence in the United States has given rise to demands for the environmental services generated by land. Environmental values were first given voice in the establishment when the National Park Service was established at the dawn of the twentieth century under Theodore Roosevelt. The trend toward environmental values continues under different auspices. Today, states and local communities have developed mechanisms to retire land from private ownership into public use. For example, in Alachua County Florida, Alachua Forever establishes funding for the purchase of environmentally sensitive ground. In California, developers often are required to invest in environmental offsets in order to develop a specific parcel of land. These offsets are intended to produce environmental flows.

The crux is that some land once deeded to the private sector is now being reclaimed by the public sector. Such transactions secure environmental benefits or environmental flows. The mechanism for capturing these environmental flows, however, may be imperfect. While a variety of trends suggest that consumers have become more environmentally aware, it is not obvious that the allocation at the margin is optimal. Unlike the allocation of goods under the price system, consumers under this allocation method do not balance marginal benefits and marginal costs.

\section{Theory}

Consider the possible outputs from a particular parcel of land (s)

$$
\left\{y_{1 s}, y_{2 s}, \cdots, y_{n s}\right\}=F\left(z_{1 s}\right)
$$

where $y_{i s}$ is the level of output $i$ that can be obtained from parcel $s, F($.$) is a surface of possible outputs (de-$ picted for three different outputs in Figure 1), and $z_{1 s}$ are a bundle of physical characteristics of parcel $s$. The total value to parcel $s$ becomes

$$
y_{1 s} R_{1 s}+y_{2 s} R_{2 s}+\cdots y_{n s} R_{n s}=\kappa
$$

where the $R_{i s}$ is the rent accruing to the use of parcel $s$ to use $i$. This relationship is depicted in Figure 1 for three outputs. Essentially, if all land was privately owned, the land owner would choose the vector of outputs $\left\{y_{1 s}, y_{2 s}, \cdots, y_{n s}\right\}$ that maximized the total rents given the characteristics of the land parcel.

We consider four different outputs from farmland: agriculture $\left(y_{1 s}\right)$, forestry $\left(y_{2 s}\right)$, urban uses $\left(y_{3 s}\right)$, and environmental flows $\left(y_{45}\right)$. The total value from all the parcels of land in a region can be written as

$$
\begin{gathered}
\sum_{s=1}^{S}\left[y_{1 s} \times R_{1}\left(\left\{y_{1 r}\right\}_{r=1}^{S}, z_{2}\right)+y_{2 s} \times R_{2}\left(\left\{y_{2 r}\right\}_{r=1}^{S}, z_{3}\right)+y_{3 s} \times R_{3}\left(\left\{y_{3 r}\right\}_{r=1}^{S}, z_{4}\right)+y_{4 s} \times R_{4}\left(\left\{y_{4 r}\right\}_{r=1}^{S}, z_{5}\right)\right] \\
\left\{y_{1 s}, y_{2 s}, y_{3 s}, y_{4 s}\right\}=F\left(z_{1 s}\right)
\end{gathered}
$$

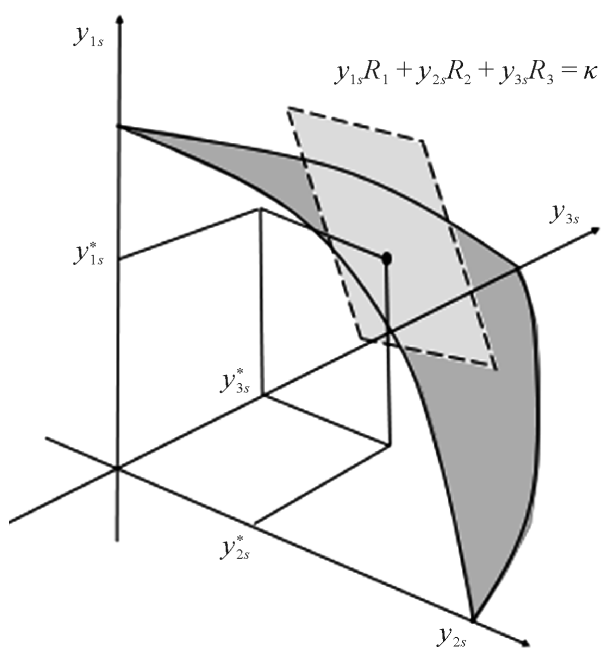

Figure 1. Production possibilities frontier for outputs for land. 
where the rents on each activity $i$ for parcel $s$ is a function of the amount of each output supplied from other parcels and a set of exogenous variables (i.e., $z_{2}$ are a set of variables that affect the profitability of agriculture such as food prices and the cost of production). These rents follow the complementary slackness conditions from general equilibrium solutions [1]

$$
\begin{aligned}
& {\left[y_{1}^{D}-\sum_{s=1}^{S} y_{1 s}\right] \times R_{1}\left(\left\{y_{1 r}\right\}_{r=1}^{S}, z_{2}\right) \leq 0} \\
& {\left[y_{2}^{D}-\sum_{s=1}^{S} y_{2 s}\right] \times R_{2}\left(\left\{y_{2 r}\right\}_{r=1}^{S}, z_{3}\right) \leq 0} \\
& {\left[y_{3}^{D}-\sum_{s=1}^{S} y_{3 s}\right] \times R_{3}\left(\left\{y_{3 r}\right\}_{r=1}^{S}, z_{4}\right) \leq 0} \\
& {\left[y_{4}^{D}-\sum_{s=1}^{S} y_{4 s}\right] \times R_{4}\left(\left\{y_{4 r}\right\}_{r=1}^{S}, z_{5}\right) \leq 0}
\end{aligned}
$$

where $y_{i}^{D}$ is the quantity of output $i$ demanded by consumers. Given these equilibrium conditions, a positive rental rate implies that the demand for output $i$ equals the amount that consumers wish to consume (or producers can profitably use in production). Alternatively, if the amount that consumers wish to consume is less than the amount supplied, no rents will accrue to this use.

A key issue in the study of land use is the jointness of production. As depicted in Figure 1, the selection of output is continuous. Any parcel of land may produce one or several outputs at the same time. For example, pasture land and commercial forest may provide habitat for wildlife. A more realistic vision of the production surface is presented in Figure 2 where the production surface is a simplex (i.e., the tradeoff between outputs is linear). In this case production typically occurs at one of the corners of the production surface. However, the production of $\left\{\tilde{y}_{1 s}, \tilde{y}_{2 s}, \tilde{y}_{3 s}\right\}$ is not on the $y_{1 s}$ axes (i.e., $\tilde{y}_{2 s}>0$ and $\tilde{y}_{3 s}>0$ ). At this point agricultural land could produce forestry outputs and urban uses. This production in a sense is free-maybe this land has sandy ridges that are used for windbreaks.

In the case of forests, commercial forests may generate significant environmental flows such as wildlife habitat. Hence, if we assume $s_{2} \subset S$ to be that set of parcels used for commercial forests, we would expect that

$$
y_{2}^{D}-\sum_{s \in s_{2}} y_{2 s}=0 \Rightarrow R\left(\left\{y_{2 r}\right\}_{r=1}^{s}, z_{3}\right) \gg 0
$$

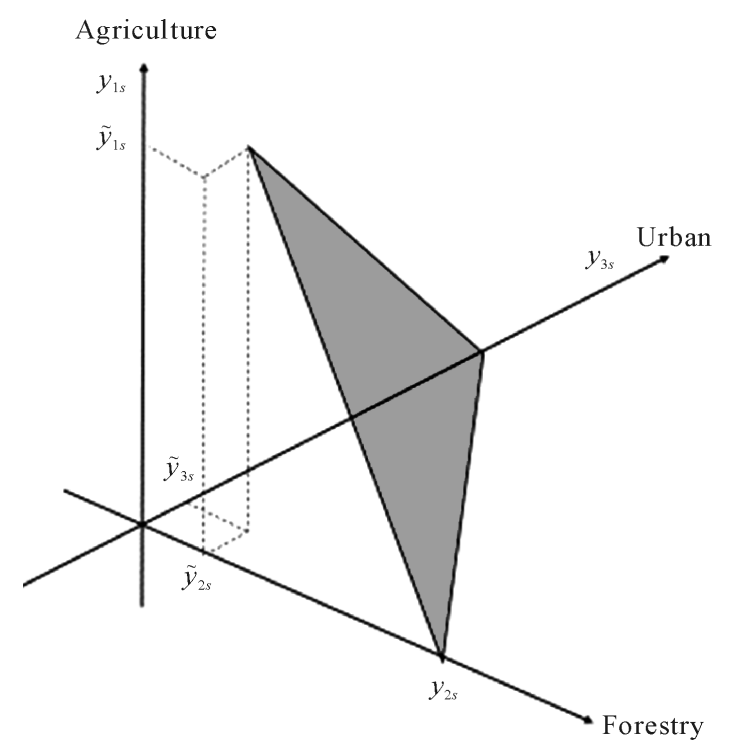

Figure 2. Linear production possibilities frontier for land outputs. 
or that the number of parcels planted to commercial forestry exactly meets the demand for products from commercial forestry implying positive rents to commercial forestry. However, in meeting these demands, the forestry sector generates environmental flows

$$
\sum_{s \in S_{2}} y_{4 s} \geq 0 .
$$

The question in analyzing the land use solution is whether this indirect source of environmental services is adequate to satisfy the demand

$$
\begin{aligned}
& y_{4}^{D}-\sum_{s \in s_{2}} y_{4 s}<0 \Rightarrow R\left(\left\{y_{4 r}\right\}_{r=1}^{s}, z_{5}\right)=0 \\
& y_{4}^{D}-\sum_{s \in s_{2}} y_{4 s} \geq 0 \Rightarrow R\left(\left\{y_{4 r}\right\}_{r=1}^{s}, z_{5}\right) \geq 0 .
\end{aligned}
$$

In the first scenario (where the rents for allocating land to environmental uses is equal to zero), no additional land will be allocated to produce environmental flows.

An underlying argument to support programs that remove land from private ownership is that the market solution has generated insufficient environmental services. The contention is that private market does not allocate enough land to generate the desired level of environmental services. This disequilibrium is typically hypothesized to be driven by a market failure such as the non-exclusionary nature of most environmental services. The argument is then that the appropriate level of environmental services will only be forthcoming if a government or philanthropic entity enters the land market to produce the desired level of services. However, once the values of the environmental flows are separated from the market transaction (i.e., land is no longer allocated across uses based on market rents), it is difficult if not impossible to answer the basic allocation question-is too much or too little land allocated to a specific use? Schmitz, Kennedy, and Hill-Gabriel [2] examine this question in the context of the buyout of sugar land from US Sugar to aid in the restoration of Florida's Everglades. They find that the cost of buying the sugar land exceeds the benefit unless the environmental impact is taken into account. Given this anomaly, they hypothesize the existence of an environmental equivalence (e.g., an amount of environmental benefits to justify the policy action). They find that the sugar buyout cost is far less than the benefits when the environmental benefits are included.

\section{Data and Methodology}

In this study, we examine the changes in the uses of land in three significant agricultural regions in the United States-the Delta States (Arkansas, Louisiana, and Mississippi), the Pacific States (California, Oregon, and Washington), and the Southeast (Alabama, Florida, Georgia, and South Carolina). These regions represent areas of environmental concern. For example, in Florida the policy questions include the effect of commercial agriculture on the Everglades as well as the urban encroachment on other environmentally sensitive lands such as wetlands. California's policy questions include the effect of urban growth in environmentally sensitive areas such as Chaparral. These states are also similar in the importance of high-valued agriculture such as fruits and vegetables to agriculture. Finally, these regions have similar levels of public and private forests in each state. The data used in this study are from Nickerson, Borchers, and Carriazo [3] who report the land allocated to cropland, pasture, forests, special uses (including rural transportation, rural, state, and national parks, and military uses), urban uses, and other (including marshes, swamps, bare rock, and other unclassified uses). The detailed data is available online [4]. Table 1 presents the land use for each region.

To analyze the change in land use over time we use the information inequality to measure the amount of statistical information in the distribution of use. Specifically, we define the statistical information index $(I)$ as

$$
I(q, p)=\sum_{i=1}^{N} q_{i} \ln \left(\frac{q_{i}}{p_{i}}\right) \quad \ni: \sum_{i=1}^{N} q_{i}=1 \text { and } \sum_{i=1}^{N} p_{i}=1
$$

where $q_{i}$ is a posterior distribution and $p_{i}$ is a prior distribution. The information index in Equation (8) was popularized by Theil [5]. Later, Theil [6] exemplifies much of this work which focuses on the use of the $I(q, p)$ to measure income inequality. In this application, $q_{i}$ is the share of income in region $i$ while $q_{i}$ is the share of population. Mathematically, as the inequality of between income shares and population shares increases the 
Table 1. Land use by region in 1000 acres, 1945-2007.

\begin{tabular}{|c|c|c|c|c|c|c|c|}
\hline Year & Total Land & Cropland & Pasture & Forest & Special & Urban & Other \\
\hline \multicolumn{8}{|c|}{ Delta States } \\
\hline 1945 & 93,006 & 22,192 & 7215 & 51,404 & 3085 & 649 & 8461 \\
\hline 1949 & 92,855 & 24,283 & 6017 & 52,715 & 3507 & 841 & 5492 \\
\hline 1954 & 92,855 & 22,162 & 8501 & 51,641 & 3556 & 815 & 6180 \\
\hline 1959 & 92,690 & 20,808 & 9358 & 53,245 & 3772 & 1118 & 4389 \\
\hline 1964 & 92,600 & 20,238 & 9433 & 54,624 & 3874 & 1194 & 3237 \\
\hline 1969 & 92,269 & 24,558 & 8433 & 50,471 & 3162 & 1200 & 4445 \\
\hline 1974 & 92,269 & 25,054 & 7449 & 50,470 & 3171 & 1407 & 4718 \\
\hline 1978 & 92,269 & 25,950 & 5777 & 49,453 & 3358 & 1849 & 5882 \\
\hline 1982 & 92,053 & 24,978 & 7390 & 47,827 & 3470 & 2122 & 6266 \\
\hline 1987 & 92,053 & 23,888 & 7307 & 47,443 & 3566 & 2416 & 7433 \\
\hline 1992 & 91,235 & 23,739 & 6357 & 48,269 & 3710 & 2717 & 6442 \\
\hline 1997 & 91,235 & 22,031 & 5534 & 50,672 & 3694 & 3065 & 6241 \\
\hline 2002 & 91,224 & 21,046 & 6246 & 50,667 & 4418 & 2251 & 6595 \\
\hline 2007 & 91,224 & 18,230 & 7209 & 52,317 & 4500 & 2284 & 6683 \\
\hline \multicolumn{8}{|c|}{ Pacific States } \\
\hline 1945 & 204,883 & 23,404 & 56,824 & 96,546 & 12,117 & 1857 & 14,135 \\
\hline 1949 & 204,699 & 27,023 & 60,550 & 97,160 & 12,474 & 2722 & 4770 \\
\hline 1954 & 204,699 & 26,243 & 59,850 & 89,905 & 14,745 & 2085 & 11,871 \\
\hline 1959 & 204,500 & 26,134 & 53,965 & 89,863 & 14,621 & 3218 & 16,699 \\
\hline 1964 & 204,422 & 25,451 & 54,307 & 89,819 & 18,948 & 3681 & 12,216 \\
\hline 1969 & 204,233 & 24,302 & 52,594 & 89,952 & 19,521 & 4117 & 13,747 \\
\hline 1974 & 204,233 & 24,786 & 53,761 & 89,747 & 19,663 & 4621 & 11,655 \\
\hline 1978 & 204,233 & 25,378 & 52,595 & 85,882 & 21,106 & 5215 & 14,057 \\
\hline 1982 & 204,156 & 25,403 & 52,296 & 85,077 & 21,890 & 5815 & 13,675 \\
\hline 1987 & 204,156 & 25,236 & 51,981 & 80,576 & 24,974 & 6755 & 14,634 \\
\hline 1992 & 203,876 & 23,928 & 54,480 & 79,278 & 23,282 & 7377 & 15,530 \\
\hline 1997 & 203,876 & 24,367 & 52,144 & 76,661 & 31,228 & 7903 & 11,573 \\
\hline 2002 & 203,840 & 23,949 & 52,337 & 78,296 & 32,344 & 7124 & 9791 \\
\hline 2007 & 203,840 & 22,110 & 57,040 & 74,021 & 36,821 & 7239 & 6610 \\
\hline \multicolumn{8}{|c|}{ Southeast States } \\
\hline 1945 & 124,450 & 26,973 & 8686 & 72,994 & 5212 & 1279 & 9306 \\
\hline 1949 & 124,242 & 27,919 & 6776 & 74,926 & 5696 & 1876 & 7049 \\
\hline 1954 & 124,242 & 24,824 & 9967 & 78,114 & 6618 & 1858 & 2861 \\
\hline 1959 & 124,068 & 21,071 & 13,939 & 76,855 & 7035 & 2904 & 2264 \\
\hline 1964 & 123,817 & 18,880 & 12,564 & 78,992 & 7352 & 3179 & 2850 \\
\hline 1969 & 123,581 & 20,424 & 10,498 & 77,061 & 7232 & 3323 & 5043 \\
\hline 1974 & 123,581 & 20,708 & 11,341 & 76,256 & 7738 & 4042 & 3496 \\
\hline 1978 & 123,581 & 21,150 & 9285 & 75,078 & 8633 & 5852 & 3583 \\
\hline 1982 & 123,635 & 20,338 & 10,387 & 73,356 & 8503 & 6815 & 4236 \\
\hline 1987 & 123,635 & 18,290 & 10,044 & 73,500 & 8630 & 8373 & 4798 \\
\hline 1992 & 123,377 & 18,053 & 9780 & 73,434 & 9245 & 8042 & 4823 \\
\hline 1997 & 123,377 & 17,982 & 9116 & 71,938 & 8984 & 9136 & 6220 \\
\hline 2002 & 123,319 & 14,824 & 8281 & 73,661 & 9099 & 8707 & 8748 \\
\hline 2007 & 123,319 & 12,483 & 10,288 & 75,150 & 9698 & 8887 & 6815 \\
\hline
\end{tabular}


information measure becomes larger. However, others have used Equation (8) as an estimation tool. Specifically, Salois, Moss, and Erickson [7] formulate the information inequality as

$$
J(v, p, y \mid \phi)=\sum_{i=1}^{N} v_{i} \ln \left(\frac{v_{i}}{\phi p_{i}+(1-\phi) y_{i}}\right)
$$

where $v_{i}$ is the share of farmland values in state $i, p_{i}$ is the share of agricultural income in state $i, y_{i}$ is a measure of the share of urban pressure in state $i$, and $\phi$ is a parameter. They then determine the significance of agricultural income versus urban pressure by selecting $\phi$ to minimize the information inequality $(J()$.$) . Hence, the$ information inequality measures the distribution between two distributions.

We are interested in two applications of the general inequality measure. First, we are interested in the difference in the distribution of land use by land type between states

$$
I_{i r t}=\sum_{s=1}^{s_{r}}\left(\frac{Q_{s t} q_{s i t}}{Q_{r i t}}\right) \ln \left(\frac{\frac{Q_{s t} q_{s i t}}{Q_{r i t}}}{Q_{s t}}\right)
$$

where $Q_{s t}$ is the share of land in state $s$ as a percent of total land in region $r, q_{s i t}$ is the share of state $s$ 's land used for land use $i$ at time $t$, and $Q_{r i t}$ is the share of land in region $r$ in use $i$ at time $t$. Essentially, $Q_{s t} q_{\text {sit }} / Q_{\text {rit }}$ is equal to the share of land use $i$ in state $s$ (e.g., across all states). If this share is higher than the overall share of state $s$ 's in total land, then that use is concentrated in that state. Alternatively, if this share is lower than the overall share of the state's land in the region, then that land use must be relatively higher in the remaining states in the region. Next, we aggregate the inequality across all states

$$
\bar{I}_{r t}=\sum_{i=1}^{N} Q_{s t} I_{s i t}
$$

where $\bar{I}_{r t}$ is the average use inequality in region $r$ at time $t$.

Following Moss, Mishra, and Erickson [8], we use the information measure to analyze the change in land use between two periods in time. We assume that the land use $i$ at time $t_{0}$ is $p_{i t_{0}}$ while the share of the same land use at time $t_{1}$ is $q_{i t_{1}}$. The change in information between the two periods is then

$$
\tilde{I}\left(t_{0}, t_{1}\right)=\sum_{i=1}^{N} q_{i t_{1}} \ln \left(\frac{q_{i t_{1}}}{p_{i t_{0}}}\right)
$$

Intuitively, if $\tilde{I}(.) \rightarrow 0$ there has been little change in land use.

\section{Results}

The inequality between land uses in each region is presented in Table 2. The overall inequality of land use is slightly higher in the Pacific States. Most of this inequality is explained by differences in the urban land use. Numerically, 78.8 percent of the urban land use across the Pacific states was in California, but California only accounts for 49.0 percent of the land in this region. This dominance falls slightly to 71.4 percent in 2007 with most of the gains occurring in Washington that increases from 13.3 percent of the urban use in 1945 to 19.3 percent in 2007. Apart from the changes in the urban use, there have been random fluctuations in the special land use. Again, California dominates this use with 71.7 percent of special land use in 1945 declining to 68.9 percent in 2007.

In the Southeastern States, Florida dominates the urban land use with 40.1 percent of all urban use in 1945 compared with 27.9 percent of all land. In addition, the Southeast is different in that the share of urban use has been relatively stable over time. Most of the changes in the differences in land use in the Southeast involve differences in pasture. Again, the difference is Florida which accounted for 46.1 percent of all pastureland in the region in 1945. This increased to 54.0 percent in 2007.

The dispersion of land use in the Delta States is fairly small. The differences occur in the other land use category. Most of this variation can be attributed to Louisiana which accounted for 60.3 percent of this category in 1945 increasing to 65.5 percent in 2007 compared to Louisiana's share of land which was 31.0 percent. Much of 
Table 2. Inequality of land use in each region, 1945-2007.

\begin{tabular}{|c|c|c|c|c|c|c|c|}
\hline Year & Cropland & Pasture & Forest & Special & Urban & Other & Average \\
\hline \multicolumn{8}{|c|}{ Delta States } \\
\hline 1945 & 0.01580 & 0.04892 & 0.00161 & 0.00168 & 0.09724 & 0.18496 & 0.02602 \\
\hline 1949 & 0.01522 & 0.02256 & 0.00065 & 0.00594 & 0.09763 & 0.16084 & 0.01643 \\
\hline 1954 & 0.00980 & 0.02312 & 0.00025 & 0.00341 & 0.06142 & 0.09049 & 0.01129 \\
\hline 1959 & 0.01193 & 0.00065 & 0.00030 & 0.00132 & 0.06250 & 0.51640 & 0.02817 \\
\hline 1964 & 0.01236 & 0.02759 & 0.00098 & 0.00482 & 0.06350 & 0.64836 & 0.02978 \\
\hline 1969 & 0.01254 & 0.00066 & 0.00016 & 0.01346 & 0.03134 & 0.31669 & 0.01961 \\
\hline 1974 & 0.01240 & 0.00131 & 0.00016 & 0.01347 & 0.01307 & 0.33931 & 0.02157 \\
\hline 1978 & 0.00984 & 0.00030 & 0.00076 & 0.01842 & 0.01710 & 0.32985 & 0.02523 \\
\hline 1982 & 0.00908 & 0.00331 & 0.00089 & 0.01950 & 0.02178 & 0.24643 & 0.02120 \\
\hline 1987 & 0.01214 & 0.00382 & 0.00132 & 0.01722 & 0.00732 & 0.19219 & 0.02051 \\
\hline 1992 & 0.01318 & 0.00642 & 0.00138 & 0.02464 & 0.02363 & 0.25793 & 0.02453 \\
\hline 1997 & 0.01842 & 0.00142 & 0.00423 & 0.02579 & 0.02829 & 0.39166 & 0.03567 \\
\hline 2002 & 0.01832 & 0.00280 & 0.00412 & 0.04693 & 0.06406 & 0.23695 & 0.02769 \\
\hline 2007 & 0.01732 & 0.01760 & 0.00522 & 0.04938 & 0.06499 & 0.26237 & 0.03113 \\
\hline \multicolumn{8}{|c|}{ Pacific States } \\
\hline 1945 & 0.03458 & 0.04496 & 0.00362 & 0.13846 & 0.20894 & 0.33894 & 0.05159 \\
\hline 1949 & 0.03041 & 0.02818 & 0.00271 & 0.13068 & 0.22195 & 0.04883 & 0.02569 \\
\hline 1954 & 0.03433 & 0.04381 & 0.00576 & 0.14340 & 0.17196 & 0.27485 & 0.04776 \\
\hline 1959 & 0.03632 & 0.03873 & 0.00544 & 0.13497 & 0.18242 & 0.16725 & 0.04343 \\
\hline 1964 & 0.04115 & 0.03240 & 0.00530 & 0.09629 & 0.20396 & 0.31661 & 0.04758 \\
\hline 1969 & 0.05180 & 0.04427 & 0.00450 & 0.10485 & 0.19805 & 0.18391 & 0.04594 \\
\hline 1974 & 0.04974 & 0.04670 & 0.00429 & 0.09991 & 0.18847 & 0.17688 & 0.04419 \\
\hline 1978 & 0.04814 & 0.05036 & 0.00700 & 0.08632 & 0.18841 & 0.20276 & 0.04958 \\
\hline 1982 & 0.04829 & 0.03462 & 0.00657 & 0.08937 & 0.18764 & 0.17270 & 0.04411 \\
\hline 1987 & 0.04634 & 0.04643 & 0.00287 & 0.06901 & 0.19838 & 0.09593 & 0.04056 \\
\hline 1992 & 0.05155 & 0.03322 & 0.00551 & 0.05843 & 0.18590 & 0.12732 & 0.04017 \\
\hline 1997 & 0.05223 & 0.04012 & 0.00865 & 0.10603 & 0.18142 & 0.04835 & 0.04577 \\
\hline 2002 & 0.04502 & 0.04794 & 0.00727 & 0.09775 & 0.14526 & 0.12570 & 0.04702 \\
\hline 2007 & 0.05164 & 0.03715 & 0.03178 & 0.11040 & 0.14422 & 0.19577 & 0.05895 \\
\hline \multicolumn{8}{|c|}{ Southeast States } \\
\hline 1945 & 0.09015 & 0.10462 & 0.00284 & 0.01048 & 0.04479 & 0.04558 & 0.03282 \\
\hline 1949 & 0.07574 & 0.13066 & 0.00217 & 0.02821 & 0.04108 & 0.01881 & 0.02844 \\
\hline 1954 & 0.05715 & 0.11441 & 0.00007 & 0.04217 & 0.00982 & 0.12467 & 0.02590 \\
\hline 1959 & 0.05536 & 0.15445 & 0.00082 & 0.04772 & 0.01297 & 0.24549 & 0.03475 \\
\hline 1964 & 0.02358 & 0.15979 & 0.00381 & 0.02657 & 0.01894 & 0.37707 & 0.03298 \\
\hline 1969 & 0.02477 & 0.19141 & 0.00655 & 0.07173 & 0.05435 & 0.14155 & 0.03587 \\
\hline 1974 & 0.01629 & 0.17373 & 0.00620 & 0.10603 & 0.08086 & 0.10446 & 0.03474 \\
\hline 1978 & 0.01223 & 0.22659 & 0.00870 & 0.09300 & 0.04086 & 0.17520 & 0.03791 \\
\hline 1982 & 0.01577 & 0.23907 & 0.00877 & 0.08652 & 0.04611 & 0.09931 & 0.03977 \\
\hline 1987 & 0.01444 & 0.21309 & 0.00938 & 0.13306 & 0.05512 & 0.13060 & 0.04311 \\
\hline 1992 & 0.01424 & 0.21631 & 0.01195 & 0.14475 & 0.04356 & 0.08541 & 0.04337 \\
\hline 1997 & 0.03012 & 0.23996 & 0.01627 & 0.12904 & 0.04967 & 0.10010 & 0.04973 \\
\hline 2002 & 0.00434 & 0.20823 & 0.01839 & 0.10480 & 0.08902 & 0.05079 & 0.04311 \\
\hline 2007 & 0.01461 & 0.18497 & 0.01384 & 0.12536 & 0.09123 & 0.02748 & 0.04329 \\
\hline
\end{tabular}


this use is attributable to Louisiana's swamps such as the Atchafalaya Basin.

Overall the inequality of land use does not show dramatic changes in land use over time. Especially apparent is the lack of reallocation to either the special or other land use categories, the exception being Florida. The land use inequality for the special category use in the Southeastern States increased from 0.01048 in 1945 to 0.12536 in 2007. This change in inequality is associated with an increase from 30.0 percent of special land use in Florida for 1945 to 51.6 percent in 2007. At the same time the other land use category for Florida declined from 32.3 percent of the Southeast in 1947 to 12.8 percent in 2007.

There is more information regarding the changes in land use across regions as depicted in Table 3. The regions have very different allocations to pasture use that persist over time. Interestingly, the Pacific States accounted for 78.1 percent of pasture use in 1945 declining only slightly to 76.5 percent in 2007 compared with the fact that the Pacific States account for 48.6 percent of land in our sample. Interestingly, the inequality in the special use substantially increases over time from 0.02625 in 1945 to 0.12037 in 2007. This growth can be primarily attributed to an increase in the special land use in the Pacific States. In 1945, 59.4 percent of the special land use occurred in the Pacific States. This amount increased to 72.2 percent in 2007.

Finally, turning to the change in land allocation over time, Table 4 presents the change in information for each state and region between 1945-1954 and 1997-2007. In general, the Delta States have seen very little change in the allocation of land between uses while the results for the other two regions are more mixed. The largest change in allocation occurs in Florida. Three categories account for this shift - the amount allocated to forestry has fallen from 64.8 percent to 43.8 percent while the amount of land allocated to special land uses have increased from 6.0 percent to 13.8 percent and the urban use increased from 1.8 percent to 11.1 percent. The next largest change was for South Carolina. Most of South Carolina's change results from a reduction in the use of land for crops, an increase in the land devoted to forests, and a slight increase in the share of land for urban uses. In the Pacific States, the changes in Washington are due to a slight decrease in the share of forestry and a rather significant increase in the special land use and urban uses of land. Similarly, the change in California is due to an increase in the special land use from 9.4 percent of California's land to 20.3 percent. A decline in forests in California is from 42.3 percent of California's land to 32.1 percent. And an increase from 1.7 percent to 5.4 percent of land allocated to urban uses.

\section{Implications and Discussion}

A widely held belief is that the increased affluence in the United States since World War II has increased the demand for environmental services and these are being met through the reallocation of land from commercial

Table 3. Inequality between regions, 1945-2007.

\begin{tabular}{|c|c|c|c|c|c|c|c|}
\hline Year & Cropland & Pasture & Forest & Special & Urban & Other & Average \\
\hline 1945 & 0.05505 & 0.18546 & 0.00490 & 0.02625 & 0.00890 & 0.00620 & 0.04577 \\
\hline 1949 & 0.04435 & 0.25053 & 0.00592 & 0.01820 & 0.01521 & 0.09184 & 0.05995 \\
\hline 1954 & 0.03529 & 0.16342 & 0.01272 & 0.02795 & 0.02240 & 0.07109 & 0.04852 \\
\hline 1959 & 0.02669 & 0.09338 & 0.01233 & 0.02155 & 0.03002 & 0.13964 & 0.03744 \\
\hline 1964 & 0.02673 & 0.10502 & 0.01460 & 0.04614 & 0.02960 & 0.07436 & 0.03800 \\
\hline 1969 & 0.05572 & 0.12883 & 0.01182 & 0.06730 & 0.02985 & 0.02374 & 0.04397 \\
\hline 1974 & 0.05586 & 0.13538 & 0.01135 & 0.06410 & 0.03502 & 0.03822 & 0.04592 \\
\hline 1978 & 0.05767 & 0.17955 & 0.01339 & 0.06327 & 0.05940 & 0.05551 & 0.05549 \\
\hline 1982 & 0.05281 & 0.14077 & 0.01222 & 0.06608 & 0.06464 & 0.03788 & 0.04817 \\
\hline 1987 & 0.04995 & 0.14464 & 0.01655 & 0.08276 & 0.07652 & 0.03689 & 0.05273 \\
\hline 1992 & 0.05694 & 0.17039 & 0.01837 & 0.06353 & 0.05142 & 0.03538 & 0.05651 \\
\hline 1997 & 0.04364 & 0.18284 & 0.02141 & 0.11431 & 0.05778 & 0.00607 & 0.06121 \\
\hline 2002 & 0.04675 & 0.18453 & 0.02094 & 0.10363 & 0.08290 & 0.01930 & 0.06242 \\
\hline 2007 & 0.04271 & 0.16220 & 0.02943 & 0.12037 & 0.08390 & 0.05809 & 0.06962 \\
\hline
\end{tabular}


Table 4. Change over time.

\begin{tabular}{ccc}
\hline State & \multicolumn{2}{c}{ Inequality } \\
\hline Arkansas & 0.01887 & \\
Louisiana & 0.02767 & 0.01651 \\
Mississippi & 0.03273 & \\
Delta States & & \\
California & 0.09043 & \\
Oregon & 0.04799 & 0.07112 \\
Washington & 0.10001 & \\
Pacific States & & \\
Alabama & 0.08107 & \\
Florida & 0.18794 & \\
Georgia & 0.08064 & 0.08728 \\
South Carolina & 0.10028 & 0.05471 \\
Southeast & & \\
Total & &
\end{tabular}

uses such as agriculture into reserves, parks and other environmental uses. For example, the farm bills have included payments for the conservation reserve program (CRP) which removed environmentally sensitive land from production. These CRP payments increase the environmental flows from agricultural lands. In addition programs such as Florida's plan to buyout US Sugar's land between Lake Okeechobee and the Everglades was intended to provide environmental benefits to the Everglades and Florida Bay between the mainland of Florida and the Florida Keys. In addition, several contend that the desire for environmental flows may limit the conversion of land into urban uses. In this study we examine the allocation of land across uses including cropland, pasture, forests, special (which includes the local, state and national parks), urban, and other. In general, changes between these uses have been small over time. There is some evidence of increased demand for environmental flows with the growth in the special category in California and Florida. However, these increases are often created by reductions in forests that also provide certain environmental amenities. In addition, there is little evidence that the desire for increased environmental flows limit the growth of urban land use over time.

The lack of private markets for environmental flows from land in most states suggests that these demands are met through traditional land uses. Forestry provides many of the same environmental flows produced by the transfer of land public ownership (i.e., parks and wildlife reserves). One of the dominant questions remains — of the land transferred from other uses into parks and recreational areas, how much is transferred at full price? Stated slightly differently, how much of the land transferred into environmental uses meets the marginal rental condition posited in the theoretical model?

Agricultural technology also has contributed to significance improvements in environmental stewardship. For example, the adoption of no-till air seeding equipment has greatly reduced soil erosion in the high plains grain growing area of North America [9]. These innovations have not only increased yields and reduced energy costs, but also reduced water use in these areas.

A debate centers on the private stewardship of land and the need for regulation. Evidence suggests that farmers and ranchers have increasingly adopted best management practices that are environmentally friendly. For example, set-backs from waterways increase the land's ability to provide water quality. Ranchers in North Florida may receive the County Alliance for Responsible Environmental Stewardship (CARES) [10] award for responsible management of nitrogen and animal runoff into Florida's springs. Similarly, areas of the private land may be declared wetlands; farmers may then follow prescribed agronomic practices in these areas. In some states, farmers are restricted from controlling wildlife activity on their land-for example elk damage in Minnesota. In return for this restriction, these farmers can apply for compensation when wildlife damage occurs. We have not taken these best management practices into account in our analysis. At one level, these regulations 
imply government provision of environmental services. This provision could be compensated (as in the case of elk damage) or uncompensated (as in the case of set-backs). Regardless of the mechanism, the level of environmental services is increased. However, since this provision does not typically occur in a market system, it is difficult to determine whether society is made better off by the acquisition. Following Schmitz, Kennedy, and HillGabriel [2], these programs imply an environmental equivalence when imposed on private land uses.

\section{References}

[1] Moss, C.B. and Schmitz, A. (2014) Valuing Carbon Recycling through Ethanol: Zero Prices for Environmental Goods. Theoretical Economics Letters, 4, 235-240. http://dx.doi.org/10.4236/tel.2014.43032

[2] Schmitz, A., Kennedy, P.L. and Hill-Gabriel, J. (2012) Restoring the Florida Everglades through a Sugar Land Buyout: Benefits, Costs, and Legal Challenges. Environmental Economics, 3, 74-85.

[3] Nickerson, C., Ebel, R., Borchers, A. and Carriazo, F. (2011) Major Uses of Land in the United States, 2007. United States Department of Agriculture, Economic Research Service; Economic Information Bulletin No. 89.

[4] Borchers, A. (2014) Major Land Uses. http://www.ers.usda.gov/data-products/major-land-uses.aspx\#25979

[5] Theil, H. (1967) Economics and Information Theory. North-Holland Publishing Company, Amsterdam.

[6] Theil, H. (1989) The Development of International Inequality 1960-1985. Journal of Econometrics, 42, 145-155. http://dx.doi.org/10.1016/0304-4076(89)90082-1

[7] Salois, M., Moss, C.B. and Erickson, K. (2012) Farm Income, Population and Farmland Prices: A Relative Information Approach. European Review of Agricultural Economics, 39, 289-307. http://dx.doi.org/10.1093/erae/jbr032

[8] Moss, C.B., Mishra, A.K. and Erickson, K. (2007) Next Year on the US Farmland Market: An Information Approach. Applied Economics, 39, 581-585. http://dx.doi.org/10.1080/00036840500447831

[9] Schmitz, A. and Moss, C.B. (2014) Mechanized Agriculture: Labor Displacement and Machine Adoption. Symposium in Honor of Wallace Huffman, Ames, 1-2 August 2014.

[10] Florida Farm Bureau (2014) Farmers CARE about Florida’s Natural Resources. Florida Agriculture, 74, 10-11. 
Scientific Research Publishing (SCIRP) is one of the largest Open Access journal publishers. It is currently publishing more than 200 open access, online, peer-reviewed journals covering a wide range of academic disciplines. SCIRP serves the worldwide academic communities and contributes to the progress and application of science with its publication.

Other selected journals from SCIRP are listed as below. Submit your manuscript to us via either submit@scirp.org or Online Submission Portal.
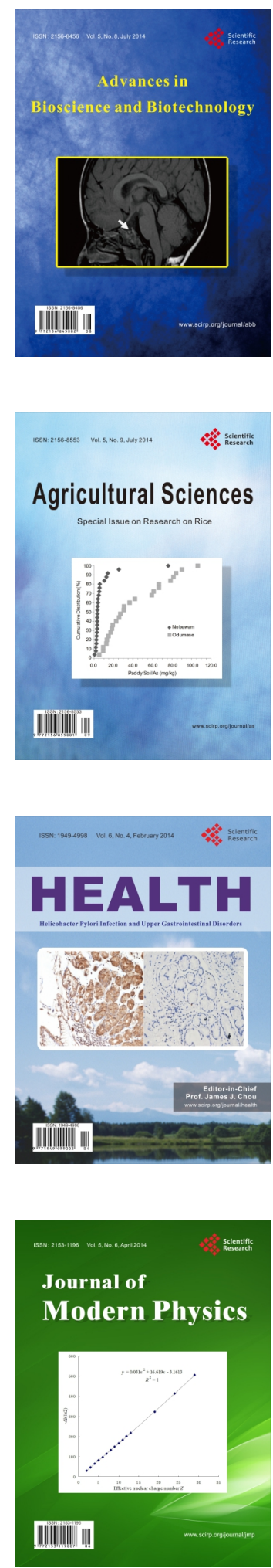
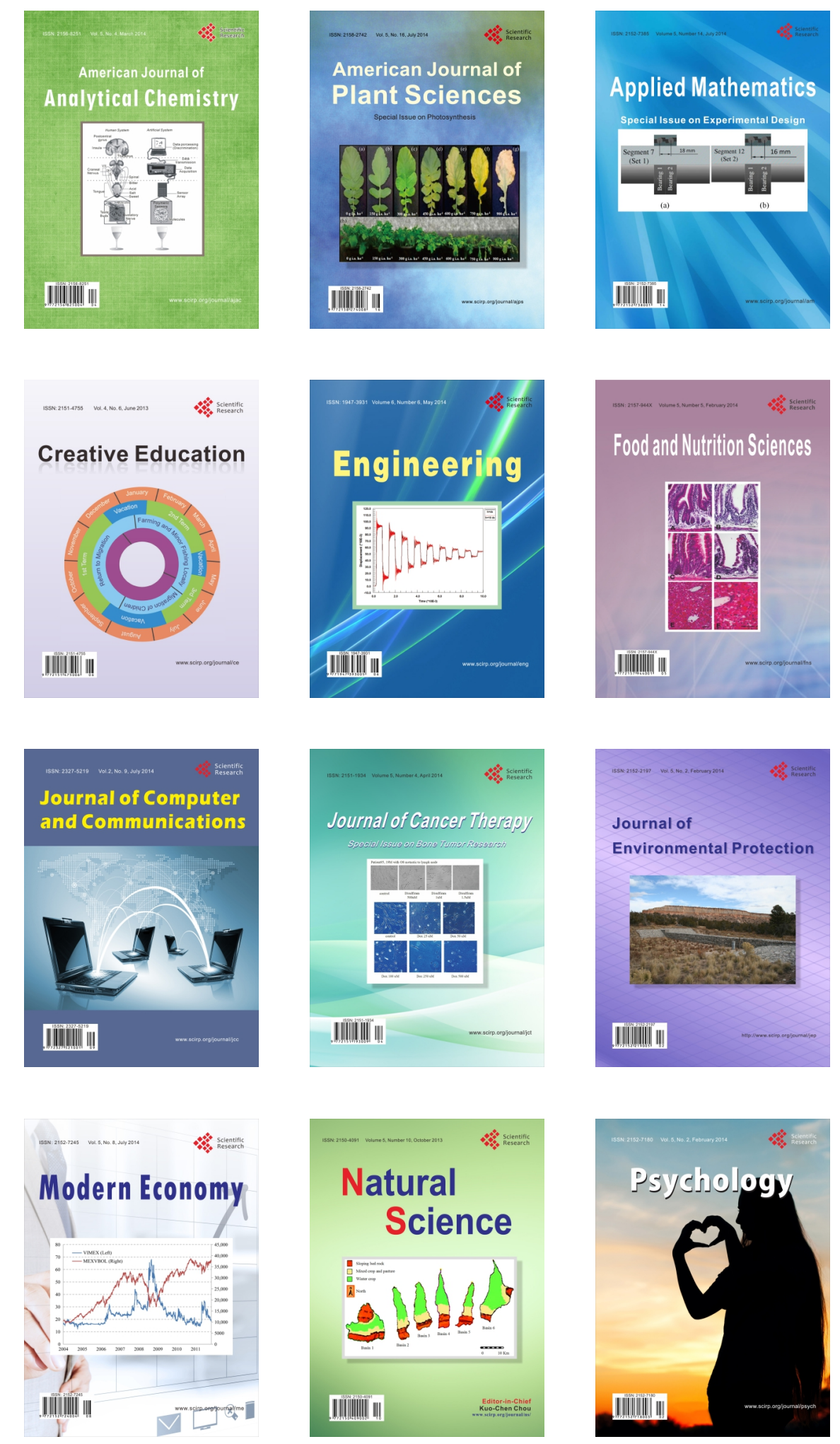